\title{
Cancer-associated fibroblasts promote cell proliferation and invasion via paracrine Wnt/IL1 $\beta$ signaling pathway in human bladder cancer
}

\author{
Fan YANG ${ }^{*}$, Zhuifeng GUO ${ }^{*}$, Chang HE, Liang QING, Hang WANG, Jiawen WU, Xuwei LU* \\ Department of Urology, Shanghai Minhang Hospital, Fudan University, Shanghai, China \\ *Correspondence: luxuwei_1108@live.com \\ ${ }^{*}$ Contributed equally to this work.
}

Received February 2, 2020 / Accepted May 26, 2020

\begin{abstract}
Bladder cancer (BC) is the most common urinary system malignancy worldwide. However, the molecular mechanisms underlying its progression remain largely unexplored. Accumulating evidence indicates that the cancer-associated fibroblasts (CAFs), major constituents of tumor stroma, play a key role in tumor development. Herein, we have successfully isolated CAFs and paired normal fibroblasts (NFs) from bladder cancer tissues. We observed that the conditional medium from bladder cancer (CM-CAF) could significantly enhance cell proliferation $(\mathrm{p}<0.01)$ and invasion capacity $(\mathrm{p}<0.01)$ of bladder cancer cell lines T24 and J82, compared to the conditional medium from NFs or 5637 cells (bladder epithelial cell control). We subsequently identified cytokine IL1 $\beta$ is enriched in CM-CAF, and a further functional study showed CAF-derived IL1 $\beta$ contributes to the aggressiveness of T2 4 cells. In mechanisms, we demonstrated that a high level of IL1 $\beta$ is capable of activating Wnt signaling in T24 cells, and Wnt signaling upregulates the expression of IL1 $\beta$, therefore forming a paracrine Wnt/IL1 $\beta$ signaling feedback to enhance the aggressive phenotype of bladder cancer cells. In addition, we treated T24 cells with CM-CAF alone, or together with Wnt signaling inhibitor XAV939. We found that the inhibition of Wnt signaling could sufficiently abolish the oncogenic effect of CAFs on bladder cancer. In conclusion, our data revealed a novel mechanism that CAFs promote cell proliferation and invasion of human BC cells through Wnt/IL1 $\beta$ signaling feedback. Inhibition of the Wnt signaling pathway may provide a promising target to block the interaction between CAF and bladder cancer cells.
\end{abstract}

Key words: bladder cancer, cancer-associated fibroblast, IL1 $\beta$, Wnt, cell proliferation, invasion

Urinary bladder cancer (BC) is one of the most common malignancies worldwide. Basically, there are 2 biologically different pathways of $\mathrm{BC}$, which is called the papillary pathway and muscle invasive pathway. Although the papillary pathway accounts for approximately $75 \%$ of newly diagnosed BC patients, $15-20 \%$ of these patients will eventually develop into muscle-invasive type, which progress to metastasis with a prognosis of 5 -year survival $<50 \%$ [1]. Therefore, it is of great significance to characterize the molecular events underlying the development of BC.

Recently, tumor stroma has been shown to play a critical role in tumor development, including BC [2-4]. It is of note that cancer-associated fibroblast (CAF), which is one of the major components in the tumor stroma, contributes to the cancer cell growth and invasion by releasing various oncogenic cytokines $[1,5]$. A growing body of studies has demonstrated that CAFs promotes multiple malignant behaviors of BC cells, such as cell proliferation, invasion, epithelial-mesenchymal transition, and even chemoresistance [6-8]. Despite these findings, the exact role of CAFs in bladder cancer and underlying mechanism(s) are still not fully understood.

In this study, we aimed to show the effect of CAFs on bladder cancer and to identify key factors secreted by CAFs. We further deciphered the mechanisms that mediated by CAFs, providing a potential target to reduce the impact of CAFs on bladder cancer cells.

\section{Materials and methods}

Cell culture and materials. Human bladder cancer cell lines T24, J82, 5637 were purchased from the Type Culture Collection of the Chinese Academy of Sciences, Shanghai, China and all cells were cultured in High Glucose DMEM medium (Thermo Fisher Scientific, Inc.) with 10\% fetal bovine serum (FBS, Thermo Fisher Scientific, Inc.), 
$100 \mathrm{U} / \mathrm{ml}$ penicillin/streptomycin at $37^{\circ} \mathrm{C}$ in $5 \% \mathrm{CO}_{2}$ humidified atmosphere. Human recombinant interleukin (IL)- $1 \beta$ and $\beta$-catenin-specific inhibitor, XAV939 were obtained from Sigma-Aldrich LLC. The reagent of $10 \mathrm{ng} / \mathrm{ml} \mathrm{IL}-1 \beta$ and $20 \mathrm{ng} / \mathrm{ml}$ were diluted in PBS according to the manufacturer's instructions. Neutralized IL-1 $\beta$ antibody was purchased from Sigma-Aldrich LLC.

NFs and CAFs cells separation and culture. Primary normal fibroblasts (NFs) and cancer-associated fibroblasts (CAFs) were derived from three bladder cancer patients who were newly diagnosed and had not been treated with radiation or chemotherapy before surgery. NFs and CAFs were isolated from the adjacent normal tissues or bladder tumor tissues as described [9]. In brief, the tissue was cut into $1 \times 1 \times 1 \mathrm{~mm}^{2}$ and then washed three times with sterile Phosphate Buffered Saline solution (PBS, HyClone, USA). Then, the tissues were digested with $160 \mu \mathrm{g} / \mathrm{ml}$ collagenase I (Sigma, USA) and $25 \mu \mathrm{g} / \mathrm{ml}$ hyaluronidase at $37^{\circ} \mathrm{C}$ for $2 \mathrm{~h}$ (Sigma, USA). The tissues were washed once with the medium and cultured in DMEM/F12 supplemented with 10\% FBS, $100 \mathrm{U} / \mathrm{ml}$ penicillin/streptomycin at $37^{\circ} \mathrm{C}$ in $5 \% \mathrm{CO}_{2}$ humidified atmosphere. The NFs or CAFs from 3 populations were pooled together to minimize inter-individual variations. The medium was replaced once every 3 days. The cells were digested with trypsin when the confluence reached $80-90 \%$. After 3 passages, NFs and CAFs were subjected to analysis, and all the analysis finished at $<10$ passages. All the culture medium of NFs and CAFs were collected for the later experiments. The cultured medium from NFs and CAFs was used as a conditioned medium (CM-NF, CM-CAF).

Cell viability. Cell viability was detected by a CCK- 8 assay (Cell Counting Kit-8, Dojindo Laboratories, Japan). Briefly, human bladder cancer cell lines T24 and J82 ( $5 \times 10^{3}$ cells/ well) were seeded into 96-well plates with $100 \mu$ culture medium for $12 \mathrm{~h}$. Then, T24 and J82 were treated with CM-5637 (cultured medium from 5637), CM-NF, CM-CAF, or drugs. After the corresponding treatment, $10 \mu \mathrm{l}$ of CCK-8 solution was added to each well of the plate, and the cells were incubated in a humidified incubator containing $5 \% \mathrm{CO}_{2}$ at $37^{\circ} \mathrm{C}$ for $1 \mathrm{~h}$. Subsequently, the absorbance was detected by a Microplate Reader (Bio-Rad, USA) at $490 \mathrm{~nm}$.

RNA extraction and quantitative real-time PCR. Total RNA was extracted from cells using TRIzol reagent (Invitrogen, USA) as previously described [10]. The first-strand cDNAs were reverse transcribed from $1 \mu$ total RNA using RevertAid First Strand cDNA Synthesis Kit (Thermo Fisher Scientific, USA) and analyzed using TB Green ${ }^{\circledR}$ Premix Ex $\mathrm{Taq}^{\mathrm{TM}}$ (Takara, Japan) by Real-Time PCR in 7500 Fast RealTime PCR detection system (ABI, USA) according to the manufacturer's protocol. The sequences of primers are listed in Supplementary Table S1. The expression levels of target genes mRNA were normalized to the levels of $\beta$-actin gene transcript and calculated using the $2^{-\Delta \Delta c t}$ method.

Western blotting. The cells were harvested and lysed in the RIPA buffer (Beyotime Biotechnology, China). The protein concentrations were detected by the Bradford protein assay (Beyotime Biotechnology, China). Equal amounts of proteins (10 $\mu \mathrm{g}$ /group) were separated by $10 \%$ SDS-PAGE gel and then transferred to a PVDF (polyvinylidene fluoride) membrane (Millipore, Germany). The membranes were blocked in 5\% non-fat milk for $1 \mathrm{~h}$, followed by incubation with the primary antibody overnight at $4^{\circ} \mathrm{C}$ with anti-IL1 $\beta$ (ab2105, Abcam, UK), anti-Vimentin (5741s), anti-E-Cadherin (14472s), anti- $\alpha$-SMA (19245s), or anti- $\beta$-actin (3700s) - all from Cell Signaling Technology, USA. Next, the membranes were incubated with the appropriate secondary antibody at room temperature for $1 \mathrm{~h}$ after the PVDF membranes were washed in TBST (TBS + 0.5\% Tween 20, Sangon, China) in $10 \mathrm{~min}$ for 3 times. Finally, protein complexes were detected by Immobilon $^{\mathrm{Tm}}$ Western HRP reagent (Millipore, USA). $\beta$-actin protein was utilized as an internal reference protein and relative protein analysis was performed using ImageJ software.

Enzyme-linked immunosorbent assay (ELISA). A human IL1 $\beta$ ELISA kit was purchased from R\&D (USA). The ELISA plate was coated with IL1 $\beta$ capture antibody able to conjugate IL1 $\beta$ in cell culture supernatants. In accordance with the vendor's instructions, supernatants of each group of cells with a serial dilution of standards were added to respective wells. The plate was sealed and incubated with gently shaking for $1 \mathrm{~h}$ at room temperature. After being washed, the plate was incubated with $100 \mu$ tetramethylbenzidine substrate for $10 \mathrm{~min}$ in the dark at room temperature and $100 \mu \mathrm{l}$ Stop solution for $1 \mathrm{~min}$ on a plate shaker. The intensity was measured at $450 \mathrm{~nm}$ employing spectrophotometry. According to the standard curves, test supernatant concentrations were calculated.

TOPFlash luciferase assays. For the Wnt pathway activity assays, $1.5 \times 10^{5}$ control T2 4 cells and T24 cells with $10 \mathrm{ng} / \mathrm{ml}$ of IL1 $\beta$ or $\mathrm{LiCl}$ seeded in triplicate in 6-well plates were transfected with TOPFlash luciferase reporter plasmid (Merk, Germany). $24 \mathrm{~h}$ after transfection, cells were lysed with Glo Lysis Buffer (Promega, USA), and then luciferase activity was measured with ONE-Glo ${ }^{\text {тм }}$ Luciferase Assay System (Promega, USA), which was normalized with TOPFlash samples. All experiments were performed at least three times and each experiment contained three technical replicates.

Statistical analysis. Statistical analyses were performed using SPSS 20.0 software (Chicago, USA). All experiments were conducted independently at least three times. All results are illustrated as the means \pm SEM. The significance of differences between groups was analyzed by Student's t-test. A p-value $<0.05$ was considered statistically significant.

\section{Results}

Characterization of primary normal fibroblasts (NFs) and cancer-associated fibroblasts (CAFs). The CAFs and NFs were successfully isolated from 3 bladder tumor samples and paired healthy bladder mucosae. As shown in Figure 1A, CAFs showed the higher mRNA expression level 
of CAF-specific genes, including fibroblast activation protein (FAP), alpha-smooth muscle actin (ACTA2), fibroblast specific protein 1 (FSP1), myofibroblast marker $\alpha$-SMA, and CD90, compared to NFs or epithelial cell control UBC 5637 $(\mathrm{p}<0.01)$. Also, our western blot demonstrated that 5637 bladder cancer had a higher level of epithelial cell marker E-cadherin, while NFs and CAFs showed higher levels of mesenchymal cell marker Vimentin. It is of note, $\alpha$-SMA was only overexpressed in CAFs (Figure 1B). Collectively, these findings showed that we have successfully isolated CAFs from bladder cancer tissues.

Conditional medium from CAFs (CM-CAF) enhanced proliferation and invasion capacity of bladder cancer cells. To investigate the oncogenic impact of CAF on bladder
A

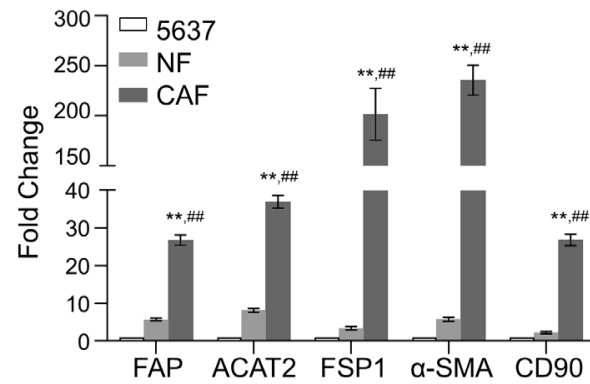

C

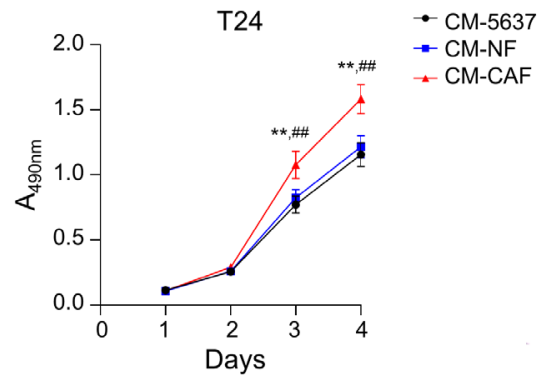

D
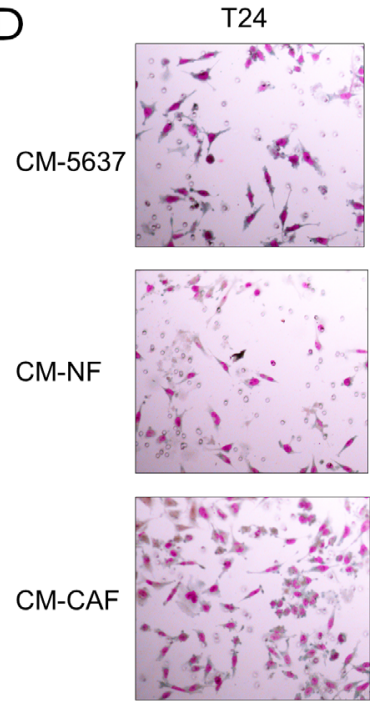

J82
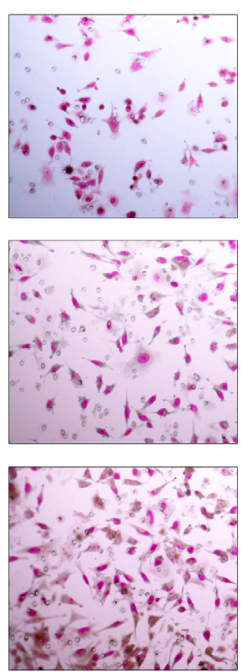

B

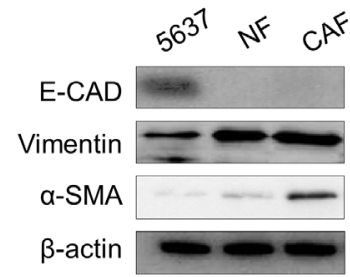

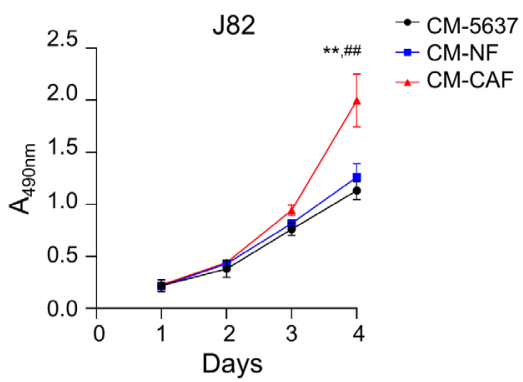

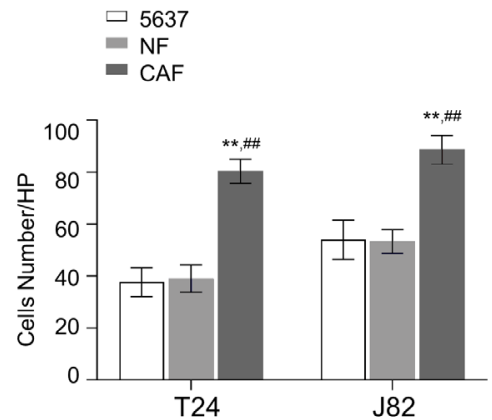

Figure 1. Conditional medium from CAFs (CAF-CM) promotes cell proliferation, migration, and invasion of bladder cancers. A) The mRNA expression levels of CAF related genes, including FAP, ACAT2, FSP1, $\alpha$-SMA, CD90 in CAFs, NFs, and 5637 cells (bladder epithelial cell control). The expression level of target genes in CAFs or NFs is calculated as fold change relative to the expression of targets in 5634 cells. ${ }^{* *}$ p $<0.01$ expression of target genes in CAFs/NFs vs. those in 5637 cells; ${ }^{* \#} \mathbf{p}<0.01$ expression of target genes in CAFs vs those in NFs. B) The expression of E-cadherin, Vimentin, a-SMA in CAFs, NFs, or 5637 cells were determined by western blot. $\beta$-actin was used as a control. C) The cell proliferation rate of T24 or J82 cells with different treatment were evaluated by CCK-8 assay $\left(n=6,{ }^{* *} p<0.01\right.$ CM-CAF/CM-NF vs. CM-5637, ${ }^{* *} p<0.01$, CM-CAF vs. CM-NF). D) Matrigeltranswell assay showed the invasive capacities of T24 or J82 cells with different treatments. The left images are representative fields of invaded cells. The right graphs indicate the invaded cell numbers per field $\left(n=3,{ }^{* *} \mathrm{p}<0.01 \mathrm{CM}-\mathrm{CAFs} / \mathrm{CM}-\mathrm{NFs}\right.$ vs. CM-5637 cells, ${ }^{* *} \mathrm{p}<0.01, \mathrm{CM}-\mathrm{CAFs}$ vs. CM-NFs). 
cancers, we collected conditional medium from CAF (CM-CAF) and treated bladder cancer cell line T24 and J82 with CM-CAF. Compared to CM from NF and 5637 cells, the bladder cancer cells with CM-CAF treatment had significant rapid growth $(\mathrm{p}<0.01$ on day 3 for $\mathrm{T} 24, \mathrm{p}<0.01$ on day 3 and 4 for J82, Figure 1C). Furthermore, we performed Matrigel-coated transwell assay to demonstrate that T24 or J82 cells with CM-CAF treatment had an enhanced invasion capacity compared to CM-NF or CM-5637 treatment, which CM-CAF increased the number of invaded cells by 3-4 times $(p<0.01$, Figure 1D). These findings suggest that CAFs may release certain factors to promote proliferation or invasion of bladder cancer cells.

High level of Interleukin $1 \beta$ (IL1 $\beta$ ) in CM-CAF led to enhanced cell proliferation or invasion of bladder cancer cells via activating the Wnt signaling pathway. As mentioned previously, CAFs may secret cytokines or inflammatory factors to have a positive role in carcinogenesis. To confirm it, we first selected several candidate cytokines or inflammatory factors and measured their expression levels in CAFs or NFs by using qPCR. As shown in Figure 2A, the mRNA expression level of candidate factors, such as IL8, IL6, or IL1 $\beta$, was upregulated in CAF, when compared to those in NFs $(\mathrm{p}<0.01)$. Since the function of IL6 and IL8 has been widely reported in bladder cancer, we began to study the role of IL1 $\beta$ in bladder cancer.

To further confirm that IL1 $\beta$ was secreted by CAF, we performed ELISA to measure IL1 $\beta$ level in CM from CAFs, NFs, or 5637 cells. As expected, IL1 $\beta$ is found significantly enriched in CM-CAF, compared to CM-NF or CM-5637 $(p<0.01$, Figure 2B). To investigate whether IL1 $\beta$ exert similar biological effects of CM-CAF on bladder cancer cells, we treated T24 cells with recombinant IL1 $\beta$ (10 ng/ml or $20 \mathrm{ng} / \mathrm{ml}$ ). As shown in Figures $2 \mathrm{C}$ and $2 \mathrm{D}$, IL $1 \beta$ can significantly promote cell proliferation and invasion of T24 cells in a dose-dependent manner $(\mathrm{p}<0.01)$. Furthermore, we found T24 treated with CM-CAF showed enhanced cell proliferation and invasion $(\mathrm{p}<0.01)$, however, the addition of IL1 $\beta$ neutralized antibody to CM-CAF can completely abolish its positive effect (Figures 2C, 2D).

Several studies have reported that IL1 $\beta$ is a positive regulator of the Wnt signaling pathway [11-13]. We then hypothesized that CAF-derived IL1 $\beta$ may exert its function through regulating the Wnt signaling pathway in bladder cancer. To prove our hypothesis, we treated T24 cells with $10 \mathrm{ng} / \mathrm{ml}$ of IL1 $\beta$ and evaluated the mRNA level of several Wnt target genes, such as c-Myc, cyclin D1, or MMP-9. Our data clearly showed that these Wnt target genes were upregulated by IL1 $\beta$ (Figure 2E). Furthermore, we added $10 \mathrm{ng} / \mathrm{ml}$ of IL1 $\beta$ or $\mathrm{LiCl}$ to T24 cells transfected with TCF reporter plasmid (TOPFLASH reporter plasmid). As shown in Figure $2 \mathrm{~F}, \mathrm{GSK} 3 \beta$ inhibitor $\mathrm{LiCl}$, which was used as a positive control of the Wnt canonical pathway activation, can significantly increase luciferase activity $(\mathrm{p}<0.01)$, suggesting that we have successfully established the TCF reporter system in
T24 cells. In this luciferase reporter assay, we also observed that luciferase activity could be dramatically induced by IL1 $\beta$ $(p<0.01)$. Together, these findings indicate that CAF-derived IL1 $\beta$ promotes proliferation or invasion of bladder cancer cells by activating the Wnt signaling pathway.

Wnt signaling inhibitor XAV939 blocks the oncogenic effect of IL1 $\beta$ on bladder cancer. The previous study has shown that IL1 $\beta$ forms a positive feedback loop with Wnt [11]. We assumed that Wnt signaling, that activated by CAF-derived IL $1 \beta$, may in turn, upregulated IL1 $\beta$ expression in bladder cancer. Also, we found $\mathrm{LiCl}$ is capable of increasing either mRNA or protein level of IL1 $\beta$ in T24 cells (Figures 3A, $3 \mathrm{~B})$. As IL1 $\beta$ was previously demonstrated as Wnt pathway downstream c-Myc target $[14,15]$, we also observed that knockdown of c-Myc can remarkably reduce the expression level of IL1 $\beta$ in T24 cells (Figures 3A, 3B), supporting our hypothesis that CAF-derived IL1 $\beta$ stimulated Wnt activation in bladder cancer and led to further increased expression of IL1 $\beta$ to promote malignant progression of bladder cancer.

Since Wnt signaling/IL1 $\beta$ feedback loop is the key effector of CAF on bladder cancer, we assumed that the Wnt pathway might be a promising therapeutic target for blocking CAF-bladder cancer cell interaction. To this end, T24 cells were treated with CM from 5637 cells, CAF, or together with Wnt inhibitor XAV939. Although CM-CAF can significantly promote cell proliferation and invasion of bladder cancer, however, inhibition of Wnt signaling can sufficiently abolish such effect by CAF (Figures 3C, 3D). We then hypothesized that the Wnt signaling/IL1 $\beta$ feedback may also function in CAF, and inhibition of Wnt can also suppress IL $1 \beta$ from CAF. We, therefore, treated CAF with $10 \mathrm{ng} / \mathrm{ml}$ of IL $1 \beta$ or $\mathrm{LiCl}$ and then transfected with TCF reporter plasmid. In line with our assumption, luciferase activity can be significantly induced by $\operatorname{IL} 1 \beta$ ( $p<0.01)$, suggesting that IL $1 \beta$, in turn, activates Wnt signaling in CAF (Figure 3E). We further measure IL1 $\beta$ level in CM from CAFs treated with Wnt inhibitor XAV939 by using ELISA. We found IL1 $\beta$ level is dramatically decreased by XAV939 ( $<<0.01$, Figure $2 \mathrm{~F})$, suggesting that inhibition of Wnt can completely block the communication between CAF and bladder cancer.

\section{Discussion}

To advance human bladder cancer treatment, the understanding of the molecular mechanism underlying tumor growth and invasion will be of great importance. Emerging evidence support that tumor stroma is actively involved in cancer development. CAFs represent the major component of the tumor microenvironment and have been reported to support tumor progression by a variety of mechanisms [16, 17]. Herein, we have successfully isolated and characterized CAF from patient biopsies. We found conditional medium from CAF greatly contributes to the enhanced cell proliferation and invasiveness of bladder cancer cells. Moreover, we have identified IL1 $\beta$ is enriched in CAF-CM, and the high 


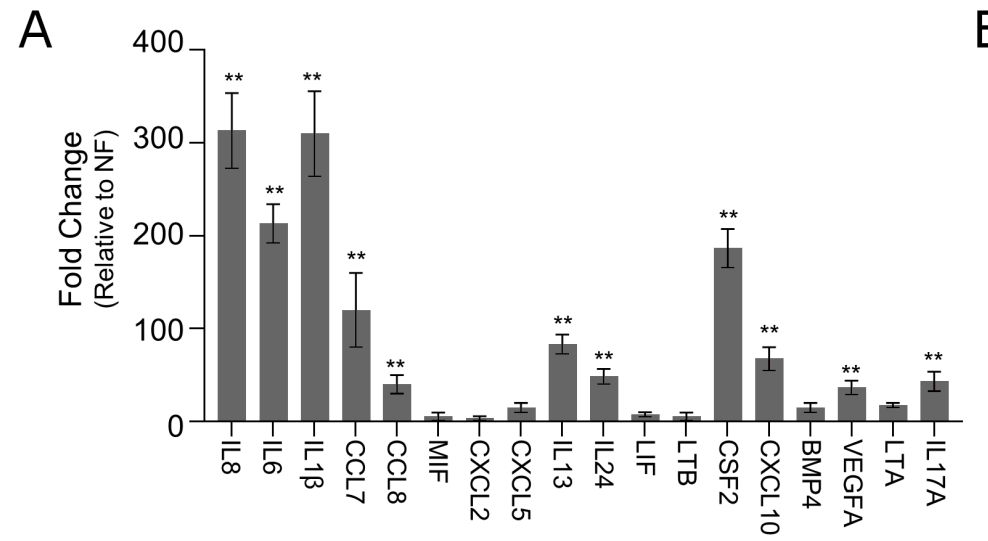

B
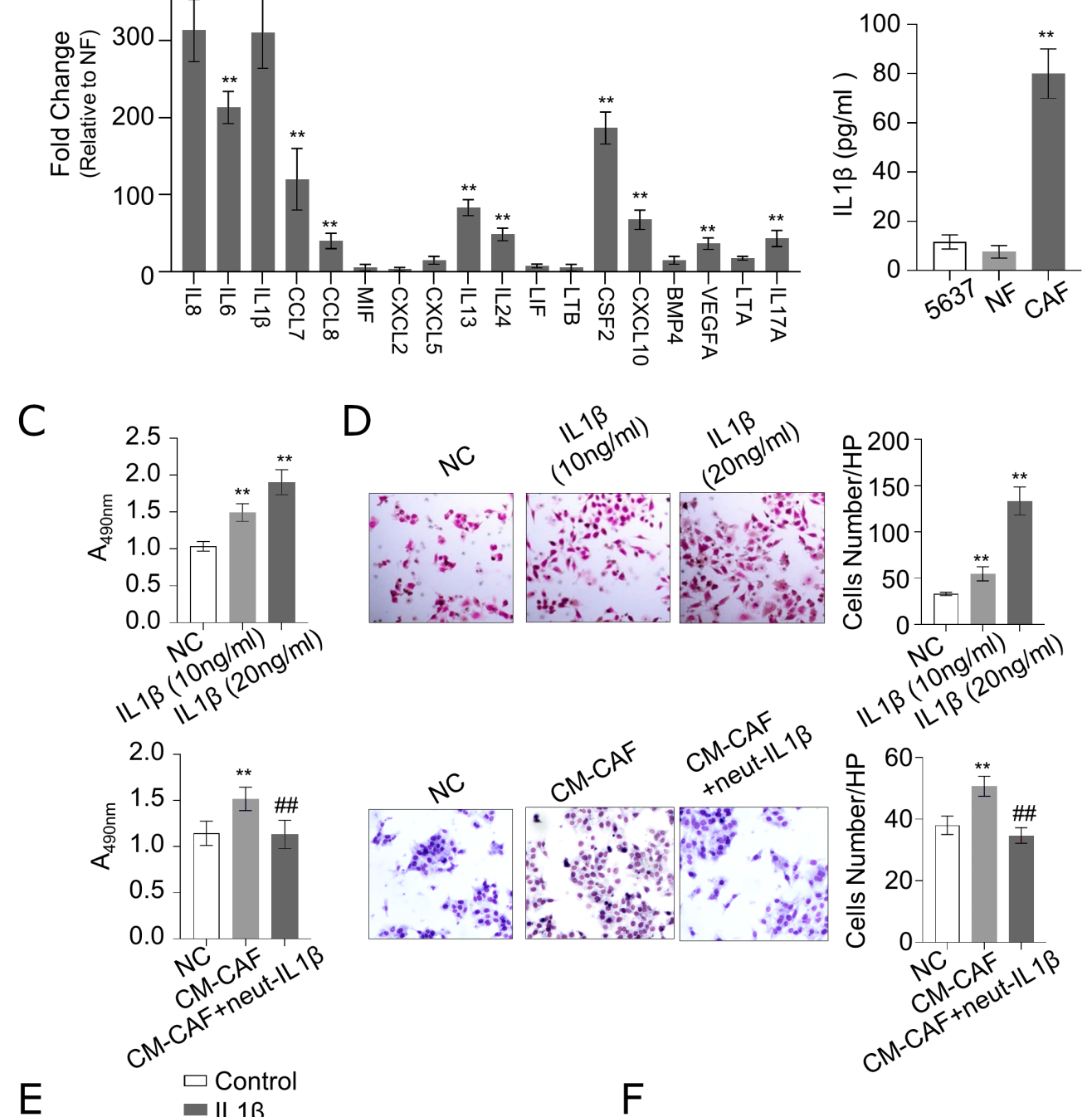

$\mathrm{E}$

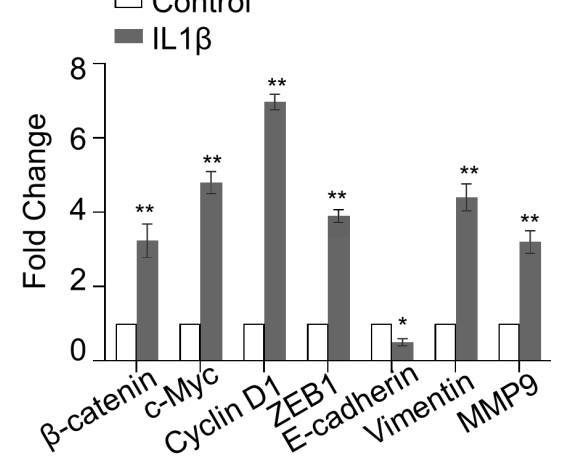

$\mathrm{F}$
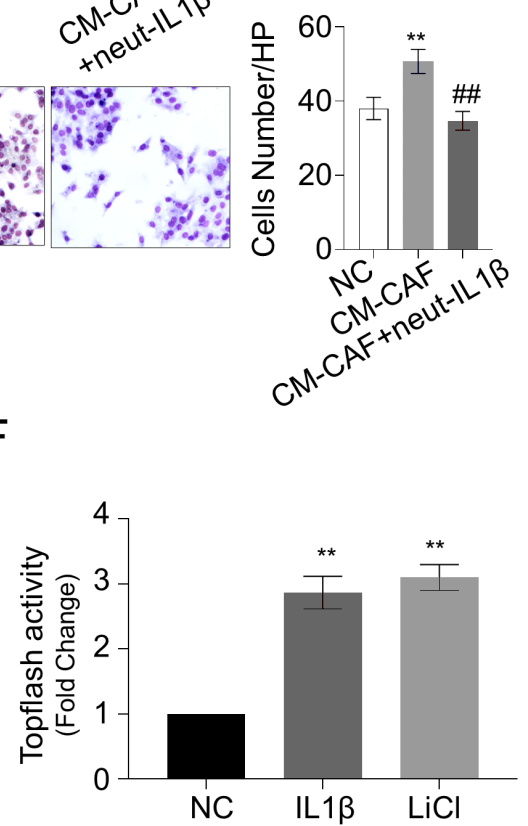

Figure 2. IL1 $\beta$ is enriched in CM-CAF, and promote cell proliferation and invasion of T24 cell via activating the Wnt signaling pathway. A) The mRNA levels of candidate cytokines or inflammatory factors in CAFs by qPCR. The expression level of target genes was calculated as fold change relative to those in NFs. ${ }^{* *} \mathbf{p}<0.01$ expression of target genes in CAFs vs. those in NFs. B) The ELISA was performed to evaluate the IL1 $\beta$ level in CM from CAFs, NFs, or 5637 cells. ${ }^{* *} p<0.01$ CM-CAFs vs. CM-5637 cells, ${ }^{* *} p<0.01, C M-C A F s$ vs. CM-NFs. T24 cells were treated with recombinant IL1 $\beta(10 \mathrm{ng} / \mathrm{ml}$ or $20 \mathrm{ng} / \mathrm{ml}$ ) or PBS (as a negative control, NC) for 3 days. C) The cell viability was measured by using CCK-8 assay. D) The cell invasion was evaluated by using the matrigel-transwell assay. ${ }^{* *} \mathrm{p}<0.01$ IL1 $\beta$ treatment vs. NC. ${ }^{* *} \mathrm{p}<0.01 \mathrm{CM}-\mathrm{CAF}$ treatment+IL1 $\beta$ antibody vs. CM-CAF treatment. E) The mRNA expression level of Wnt targets was evaluated in T24 controls cells or cells with IL1 $\beta$ treatment. ${ }^{* *} p<0.01$ IL1 $\beta$ treatment vs. NC, ${ }^{*} p<0.05$ IL1 $\beta$ treatment vs. NC. F) The luciferase reporter (TOPFLASH) assay was performed to compare luciferase activity in T24 control cells or cells treated with IL1 $\beta$ or LiCl. ${ }^{* *} \mathbf{p}<0.01$ IL1 $\beta$ treatment or LiCl treatment vs. NC. 

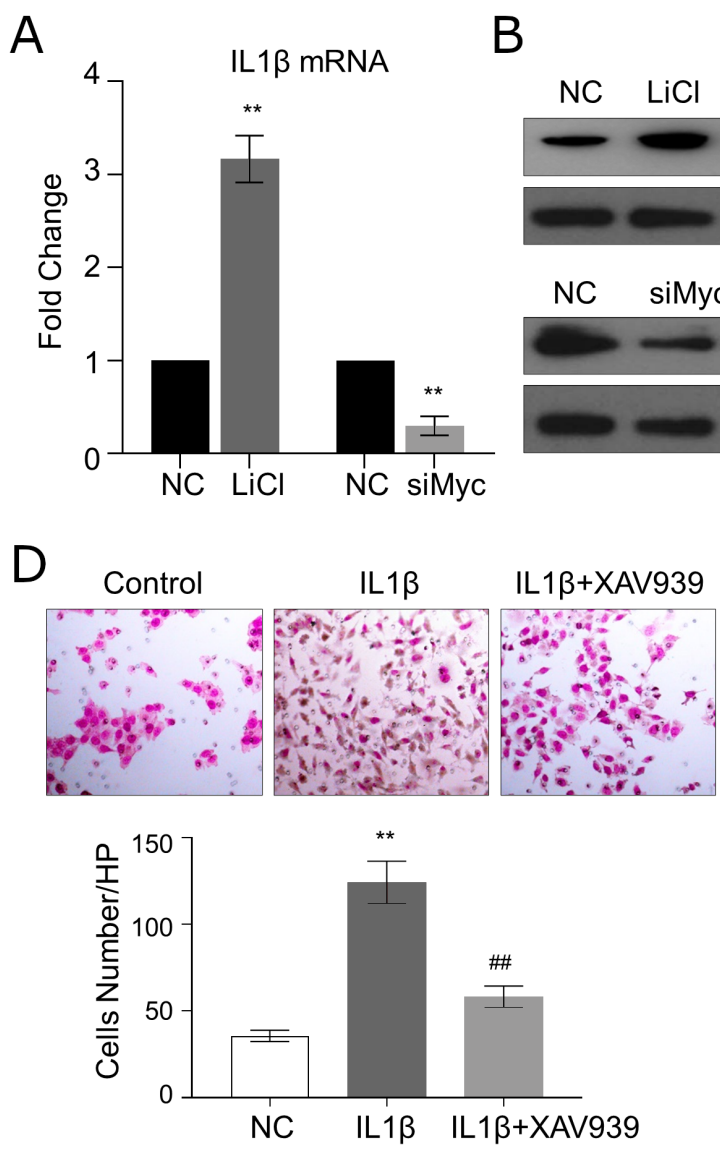

C

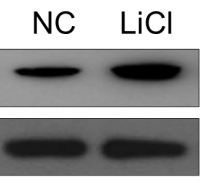

IL1 $\beta$
$\beta$-actin

NC siMyc

IL1 $\beta$
$\beta$-actin

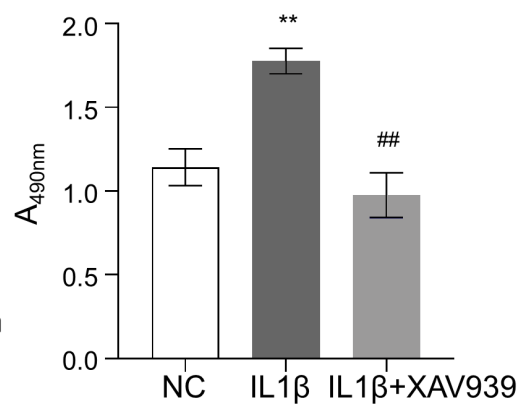

$\mathrm{E}$

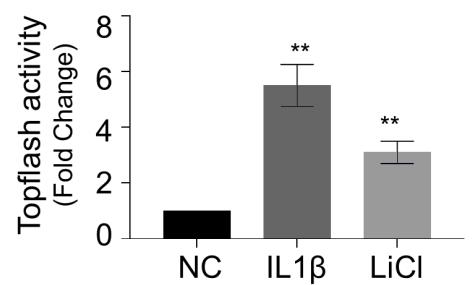

$\mathrm{F}$

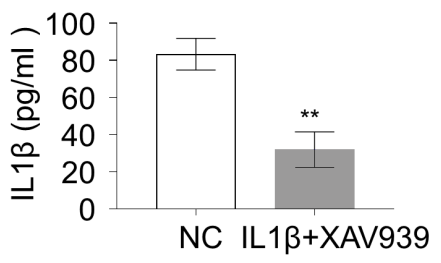

G

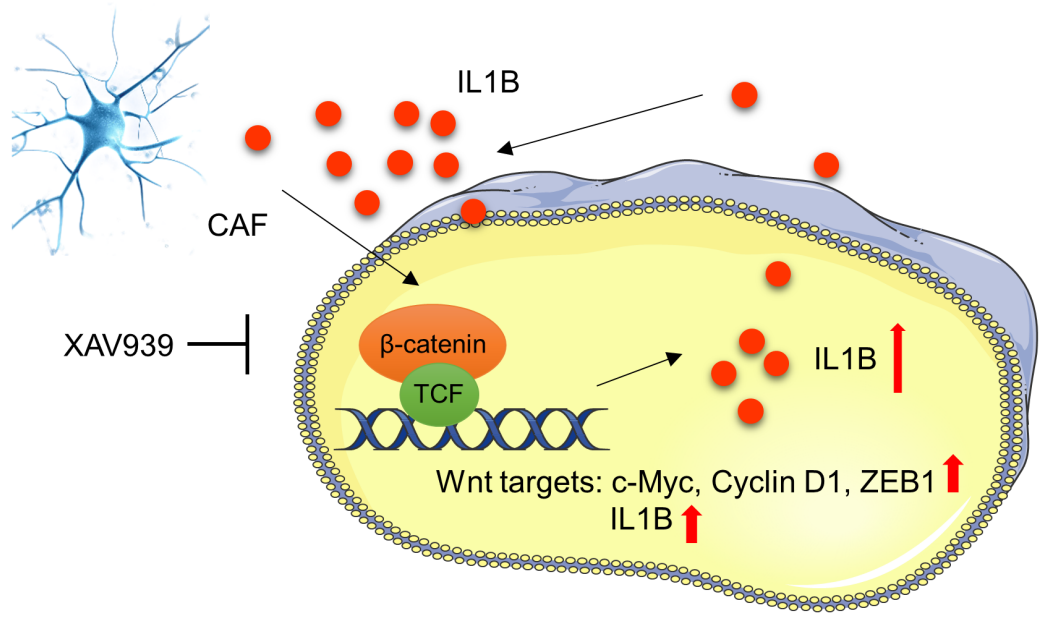

Figure 3. Blocking the IL1 $\beta$-Wnt feedback loop by Wnt inhibitor XAV939 significantly suppressed cell proliferation or invasion of T24 bladder cancer cells. A) The mRNA expression level of IL1 $\beta$ was examined by qPCR in control cells (negative control, NC), or T24 cells treated either LiCl or c-Myc siRNAs. The expression level in the treatment group is calculated as fold change relative to the level in the control group $(\mathrm{NC}),{ }^{* *} \mathrm{p}<0.01$, treatment group vs. NC. B) The protein level of IL1 $\beta$ was evaluated by western blotting assay in T24 control cells or cells with either LiCl or c-Myc siRNAs treatment. T24 cells were treated with PBS (as a negative control, NC), CAF-CM alone, or together with XAV939 for 3 days. C) The cell viability was measured by using CCK-8 assay. D) The cell invasion was evaluated by using the matrigel-transwell assay. ${ }^{\star *} \mathbf{p}<0.01 \mathrm{CAF}-\mathrm{CM}$ treatment vs. NC. ${ }^{* \#} \mathbf{p}<0.01 \mathrm{CAF}-\mathrm{CM}$ treatment vs. CAF-CM plus XAV939 treatment. E) The luciferase reporter (TOPFLASH) assay was performed to compare luciferase activity in CAFs control cells or cells treated with IL1 $\beta$ or LiCl. ${ }^{* *} \mathrm{p}<0.01 \mathrm{IL} 1 \beta$ treatment or LiCl treatment vs NC. F) The ELISA was performed to evaluate the IL1 $\beta$ level in CM from CAFs control cells (NC) or cells treated with XAV939. ${ }^{\star *} \mathbf{p}<0.01$ XAV939 treatment vs NC. G) The proposed mechanisms CAFs exert their functions on bladder cancer. 
level of IL1 $\beta$ stimulates Wnt signaling in bladder cancer cells. Interestingly, we also showed that activation of Wnt, in turn, upregulated IL1 $\beta$ expression to generate a positive feed loop, therefore enhancing the aggressiveness of bladder cancer cells. Last, but not least, we treated bladder cancer cells with Wnt inhibitor XAV939, and CM-CAF showed less effect on bladder cancer, indicating XAV939 may serve as a potential drug to inhibit interplay between bladder cancer cells and CAFs.

The amount of evidence showed hyperactivity of Wnt signaling promote the development of bladder cancer [18]. Compared to the frequent mutated APC or Axin 1 in gastrointestinal cancers, few mutations of Wnt pathway components were reported in bladder cancer, requiring a better understand of how Wnt signaling is activated to promote bladder cancer cell invasion. Intriguingly, microenvironmental IL1 $\beta$ has been shown to enhance tumor aggressiveness in multiple cancer types [19-21]. We have found that CAFs can significantly increase IL1 $\beta$ level, and therefore promoting cell proliferation and invasion of T24 cells. We then investigated whether the accumulation of IL1 $\beta$ is correlated with activation of Wnt signaling pathways. Several studies suggest that IL1 $\beta$ could enhance Wnt signal via inhibiting DKK1 or indirectly interacting with intracellular NF-kB and CREB signaling $[12,13,22]$. Based on these findings, we treated T24 cells with recombinant IL1 $\beta$ and showed remarkably upregulated expression of Wnt targets. In consistent, IL1 $\beta$ could also stimulate the activity of TOPFLASH reporter, highlighting novel insights that the accumulation of IL $1 \beta$ by CAFs is one of the mechanisms for Wnt activation in bladder cancer.

Since IL1 $\beta$ has been confirmed as the c-Myc downstream target, we hypothesized that activation of the Wnt signal by CAF-derived IL1 $\beta$ could further boost the IL1 $\beta$-Wnt signal to promote cell growth and invasion of bladder cancer cells. Indeed, we found inhibition of c-Myc or enhance Wnt signal by $\mathrm{LiCl}$ could affect the expression of IL1 $\beta$ in T24 cells. Based on the important role of IL1 $\beta$-Wnt feedback in bladder cancer, we aimed to find a therapeutic target for blocking these regulatory circuits. By using Wnt inhibitor XAV939, we found CM-CAF showed impaired oncogenic effect on bladder cancer, indicating that inhibition of Wnt can completely abolish the effect by CAFs. Furthermore, we also found IL1 $\beta /$ Wnt feedback functions not only in bladder cancer cells but CAFs as well. IL1 $\beta$ can significantly increase Wnt signal activity in CAFs, while inhibition of Wnt signaling led to the reduced IL1 $\beta$ secretion, suggesting that Wnt inhibitors can block the communication between CAFs and cancer cells.

In summary, our work proposes the interconnected mechanisms that CAFs exert their functions on bladder cancer. We reported a constitutive activation of the Wnt signal by CAFs-derived IL1 $\beta$, which can be further enhanced by the Wnt-IL1 $\beta$ positive feed loop in bladder cancer. The pharmacological inhibition of Wnt/c-Myc can significantly reduce the production of IL1 $\beta$, providing a potential drug target for BC cell proliferation and invasion.

Supplementary information is available in the online version of the paper.

\section{References}

[1] WU XR. Urothelial tumorigenesis: a tale of divergent pathways. Nat Rev Cancer 2005 Sep; 5: 713-725. https://doi. org/10.1038/nrc1697

[2] WANG L, SACI A, SZABO PM, CHASALOW SD, CASTILLO-MARTIN M et al. EMT- and stroma-related gene expression and resistance to PD-1 blockade in urothelial cancer. Nat Commun 2018; 9: 3503. https://doi.org/10.1038/ s41467-018-05992-x

[3] CHEN J, MA L, ZHANG N, ZHU Y, ZHANG K et al. Mesenchymal Stem Cells Promote Tumor Progression via Inducing Stroma Remodeling on Rabbit VX2 Bladder Tumor Model. Int J Biol Sci 20; 14: 1012-1021. https://doi.org/10.7150/ ijbs. 25200

[4] PICHLER R, FRITZ J, ZAVADIL C, SCHAFER G, CULIG $Z$ et al. Tumor-infiltrating immune cell subpopulations influence the oncologic outcome after intravesical Bacillus Calmette-Guerin therapy in bladder cancer. Oncotarget 2016; 7: 39916-39930. https://doi.org/10.18632/oncotarget.9537

[5] LEBLEU VS, KALLURI R. A peek into cancer-associated fibroblasts: origins, functions and translational impact. Dis Model Mech 2018; 11: dmm029447. https://doi.org/10.1242/ dmm. 029447

[6] WANG J, ZHANG N, PENG M, HUA X, HUANG C et al. p85alpha Inactivates MMP-2 and Suppresses Bladder Cancer Invasion by Inhibiting MMP-14 Transcription and TIMP2 Degradation. Neoplasia 2019; 21: 908-920. https://doi. org/10.1016/j.neo.2019.07.007

[7] LONG X, XIONG W, ZENG X, QI L, CAI Y et al. Cancerassociated fibroblasts promote cisplatin resistance in bladder cancer cells by increasing IGF-1/ERbeta/Bcl-2 signalling. Cell Death Dis 2019; 10: 375. https://doi.org/10.1038/ s41419-019-1581-6

[8] GOULET CR, CHAMPAGNE A, BERNARD G, VANDAL $D, C H A B A U D S$ et al. Cancer-associated fibroblasts induce epithelial-mesenchymal transition of bladder cancer cells through paracrine IL-6 signalling. BMC Cancer 2019; 19: 137. https://doi.org/10.1186/s12885-019-5353-6

[9] RYHANEN EM, HEISKANEN I, SINTONEN H, VALIMAKI MJ, ROINE RP et al. Health-related quality of life is impaired in primary hyperparathyroidism and significantly improves after surgery: a prospective study using the 15D instrument. Endocr Connect 2015; 4: 179-186. https://doi. org/10.1530/EC-15-0053

[10] MAHABIR R, TANINO M, ELMANSURI A, WANG L, KIMURA T et al. Sustained elevation of Snail promotes glial-mesenchymal transition after irradiation in malignant glioma. Neuro Oncol 2014; 16: 671-685. https://doi. org/10.1093/neuonc/not239 
[11] MILOSEVIC V, KOPECKA J, SALAROGLIO IC, LIBENER $\mathrm{R}$, NAPOLI $F$ et al. Wnt/IL-1beta/IL-8 autocrine circuitries control chemoresistance in mesothelioma initiating cells by inducing ABCB5. Int J Cancer 2020; 146: 192-207. https:// doi.org/10.1002/ijc.32419

[12] EYRE R, ALFEREZ DG, SANTIAGO-GOMEZ A, SPENCE $\mathrm{K}$, MCCONNELL JC et al. Microenvironmental IL1beta promotes breast cancer metastatic colonisation in the bone via activation of Wnt signalling. Nat Commun 2019; 10: 5016. https://doi.org/10.1038/s41467-019-12807-0

[13] YOSHIDA Y, YAMASAKI S, OI K, KURANOBU T, NOJIMA T et al. IL-1beta Enhances Wnt Signal by Inhibiting DKK1. Inflammation 2018; 41: 1945-1954. https://doi. org/10.1007/s10753-018-0838-z

[14] AUMILLER V, BALSARA N, WILHELM J, GUNTHER A, KONIGSHOFF M. WNT/beta-catenin signaling induces IL-1beta expression by alveolar epithelial cells in pulmonary fibrosis. Am J Respir Cell Mol Biol 2013; 49: 96-104. https:// doi.org/10.1165/rcmb.2012-0524OC

[15] SHCHORS K, SHCHORS E, ROSTKER F, LAWLOR ER, BROWN-SWIGART L et al. The Myc-dependent angiogenic switch in tumors is mediated by interleukin 1beta. Genes Dev 2006; 20: 2527-2538. https://doi.org/10.1101/gad.1455706

[16] LIU T, ZHOU L, LI D, ANDL T, ZHANG Y. Cancer-Associated Fibroblasts Build and Secure the Tumor Microenvironment. Front Cell Dev Biol 2019; 7: 60. https://doi. org/10.3389/fcell.2019.00060
[17] FIORI ME, DI FRANCO S, VILLANOVA L, BIANCA P, STASSI G et al. Cancer-associated fibroblasts as abettors of tumor progression at the crossroads of EMT and therapy resistance. Mol Cancer 2019; 18: 70. https://doi.org/10.1186/ s12943-019-0994-2

[18] GARG M, MAURYA N. WNT/beta-catenin signaling in urothelial carcinoma of bladder. World J Nephrol 2019; 8: 83-94. https://doi.org/10.5527/wjn.v8.i5.83

[19] TULOTTA C, LEFLEY DV, FREEMAN K, GREGORY WM, HANBY AM et al. Endogenous Production of IL1B by Breast Cancer Cells Drives Metastasis and Colonization of the Bone Microenvironment. Clin Cancer Res 2019; 25: 2769-2782. https://doi.org/10.1158/1078-0432.CCR-18-2202

[20] CASTANO Z, SAN JUAN BP, SPIEGEL A, PANT A, DECRISTO $\mathrm{MJ}$ et al. IL-1beta inflammatory response driven by primary breast cancer prevents metastasis-initiating cell colonization. Nat Cell Biol 2018; 20: 1084-1097. https://doi. org/10.1038/s41556-018-0173-5

[21] ZHANG D, LI L, JIANG H, LI Q, WANG-GILLAM A et al. Tumor-Stroma IL1beta-IRAK4 Feedforward Circuitry Drives Tumor Fibrosis, Chemoresistance, and Poor Prognosis in Pancreatic Cancer. Cancer Res 2018; 78: 1700-1712. https://doi.org/10.1158/0008-5472.CAN-17-1366

[22] SUN J, CHEN J, CAO J, LI T, ZHUANG S et al. IL-1 $\beta$ stimulated $\beta$-catenin up-regulation promotes angiogenesis in human lung-derived mesenchymal stromal cells through a NF- $\kappa \mathrm{B}$-dependent microRNA-433 induction. Oncotarget 2016; 7: 59429-59440. https://doi.org/10.18632/oncotarget.10683 